\title{
Designing extra-curricular dance programs: UK physical education and dance teachers' perspectives
}

\author{
Simon J. Sebire ${ }^{1 *}$, Jade McNeill ${ }^{1}$, Laura Pool ${ }^{1}$, Anne M. Haase $^{1}$, Jane Powell ${ }^{2}$, Russell Jago ${ }^{1}$ \\ ${ }^{1}$ Centre for Exercise, Nutrition \& Health Sciences, School for Policy Studies, University of Bristol, Bristol, UK; \\ *Corresponding Author: simon.sebire@bristol.ac.uk \\ ${ }^{2}$ Faculty of Health \& Life Sciences, University of the West of England, Bristol, UK
}

Received 19 December 2012; revised 20 January 2013; accepted 27 January 2013

\begin{abstract}
Many girls do not engage in sufficient physical activity (PA). Dance is a popular form of PA among UK secondary school-aged girls and extracurricular dance programs delivered by dance specialists may provide an alternative way to increase PA amongst girls aged 11 - 12. The purpose of this study was to explore the views of physical education and dance teachers on the structure, content and delivery of an extra-curricular dance-based PA intervention for adolescent girls. Methods: Semi-structured qualitative interviews were conducted with eleven physical education teachers and eleven dance teachers, and were analyzed using thematic analysis. Results: Themes identified addressed key logistical and content/delivery-based factors to be considered when designing a dancebased PA intervention. Logistical factors included optimizing participant recruitment and aligning external providers with school behavior management policies. Content/delivery factors focused on teacher-student rapport, facilitating dance competence, and balancing teacher and student-led time. Conclusions: This formative study highlighted that an extra-curricular dancebased PA intervention would be welcomed in UK schools. A number of considerations central to the design and delivery of such a program were identified from key user groups which can be used to inform the development of schoolbased dance (and non-dance) interventions aimed at increasing PA amongst adolescent girls.
\end{abstract}

Keywords: Physical Activity Intervention; Intervention Design; Qualitative Research

\section{INTRODUCTION}

Physical activity (PA) is associated with lower levels of cardiovascular risk and type 2 diabetes among children $[1,2]$, and is linked with improved psychological health including emotional well being, self esteem and confidence [3]. Despite this, many young people do not meet PA guidelines of 60 minutes of moderate-tovigorous PA per day [4] and there is an age-related decline in PA during childhood, particularly among girls [5] during the transition from primary (elementary) to secondary (high) school [6]. Therefore, childhood and adolescence are key periods to promote PA and the development and evaluation of interventions to target $\mathrm{PA}$ during youth is a priority [7].

Schools are a popular setting for the implementation of interventions, due to their frequent contact with most children. However, many school-based interventions have not yielded increases in youth PA [8]. Due to the pressures to raise academic standards and improve test scores, curriculum time devoted to PA and physical education (PE) is limited [9]. Therefore, there is a need for interventions delivered at school, but outside of curriculum time.

Dance is a highly favored form of PA among UK secondary school-aged girls [10]. Dance does not require exceptional abilities or equipment and can motivate and excite young people, develop team working and creative thinking [11,12]. Importantly, participating in dance contributes towards moderate-to-vigorous PA amongst 11 - 18 years old girls [13].

However, although dance is part of the UK PE national curriculum, it is usually only taught during one term for six weeks. Furthermore, an audit conducted by the Youth Sports Trust [14] raised concerns about the quality and equality of school-based dance provision. It was identified that only $8 \%$ of teachers had a dance specialism and $60 \%$ of PE teachers were generalists without dance qualifications. Limited curriculum time, and the 
skills and expertise needed to teach dance suggests that extra-curricular dance programs delivered by dance specialists may provide an alternative way to increase PA amongst adolescent girls aged 11 - 12 [15].

Guidance for the design and implementation of school-based dance programs is not available. However it is crucial to conduct and disseminate formative and feasibility research so that interventions can be developed which align with best practice and user group experience [16]. As such, the first aim of the present formative study was to explore dance and PE teachers' views on key considerations for the structure, content and delivery of a dance-based PA intervention for adolescent girls. PE teachers' views were sought on schoolbased issues (e.g., logistics, dance provision $\&$ perceived interest) and dance teachers' views were sought on delivering dance-based PA programs.

Incorporating theoretical frameworks in to the development of interventions facilitates an understanding of the process and mechanisms by which interventions might work [17]. However, the apriori selection of a given theory may exclude potentially important factors that are part of the intervention context (e.g., dance). As such, the second aim of this study was to use the views of the dance and PE teachers to identify a theoretical framework which could guide the development of a dance-based afterschool PA intervention.

\section{METHODS}

\subsection{Participants}

Physical education teachers were recruited from 10 secondary schools, without a dance specialism, from Bristol (UK) to represent a range of socio-economic status (SES) groups. Eleven nationally-recognized expert female dance teachers were recruited using a snowballing method. To be eligible for inclusion, dance teachers were required to have a minimum of two years teaching experience, hold dance education qualifications equivalent to UK A-Level and have worked with the target population for a minimum of one year. Participants included current dance teachers, dance educators, national and local dance development officers and school-based dance leads. All participants provided written informed consent. The study was approved by a University ethics committee.

\subsection{Procedure}

Semi-structured interviews were employed to allow the $\mathrm{PE}$ and dance teachers to talk freely and openly within a framework of topics. Twenty two interviews (11 dance teachers and $11 \mathrm{PE}$ teachers) were conducted either face-to-face or by telephone by two trained interviewers and were digitally recorded (Mean duration $=40$ minutes; range $=30$ - 50 minutes).

A semi-structured interview guide was developed in collaboration with an expert with extensive experience in dance teaching and education. It aimed to facilitate open discussions and prompts were used to gather in-depth perspectives. The PE teachers' interview explored: 1) logistical issues within a school environment (e.g., facilities, timetabling activities and travel/safety concerns); 2) how to structure the dance program and its content and 3) recruitment into an extra-curricular dance program. The dance instructors' interview focused on content and delivery of dance sessions for adolescent girls. Topics included: 1) barriers to participation in a dance program; 2) successful strategies to teach dance, aid development and progression; 3) effective ways to retain participation and 4) the content of the session, (e.g., enhancing enjoyment and behavior management strategies). Following completion of 22 interviews it was agreed that saturation had been reached.

\subsection{Data Analysis}

Recordings were transcribed verbatim, anonymised and transcripts were imported into NVivo (Version 8, QSR, Southport, UK). As the data were considered exploratory, we adopted a thematic analysis approach [18] using three stages. First, transcripts were read line-byline and annotated with codes that described notable content. Second, a different team member reviewed all annotated transcripts to scrutinize codes and themes and to identify any differences in interpretations. Another team member acted as the arbitrator of any differences in interpretation. Third, codes were analyzed for links in order to generate themes.

\section{RESULTS}

Ten themes were identified which highlighted factors pertinent to the design and delivery of a school-based extra-curricular dance program (Table 1). The themes were grouped into two higher-order themes; 1) Perceived Need and School Logistics contained themes addressing current dance provision, school logistic issues, participant recruitment, program cost and behavior management and 2) Dance Program Content contained five themes addressing dance genre, building enjoyment, teacher-student rapport, fostering ownership and performance opportunities. All themes are discussed in detail below.

\subsection{Theme 1: Perceived Need and School Logistics}

Dance provision. All of the PE teachers highlighted a lack of dance provision in their school and a need for a dance program. In addition, the majority of PE teach- 
Table 1. Summary of themes.

\begin{tabular}{|c|c|}
\hline \multicolumn{2}{|r|}{ Theme 1: Perceived need \& school logistics } \\
\hline Dance provision & $\begin{array}{l}\text { - } \quad \text { Lack of dance in schools } \\
\text { - } \quad \text { PE teachers not confident to deliver dance session }\end{array}$ \\
\hline School-based logistics & $\begin{array}{ll}- & \text { Facilities \& space } \\
\text { - } & \text { Timetabling to avoid clashes }\end{array}$ \\
\hline Participant recruitment & $\begin{array}{l}\text { - } \quad \text { Recruit using "taster sessions" } \\
\text { - } \quad \text { Personal "live link" rather than printed materials }\end{array}$ \\
\hline Cost of program & $\begin{array}{l}\text { - } \quad \text { Payment may prevent participation \& bias sample } \\
\text { - } \quad \text { Payment may increase commitment to program }\end{array}$ \\
\hline Behavior management and expectations & $\begin{array}{ll}- & \text { Align rules with behavior policies within school } \\
\text { - } & \text { Establish agreed expectations for teachers and pupils } \\
\text { - } & \text { Balance rules with pupil input }\end{array}$ \\
\hline \multicolumn{2}{|r|}{ Theme 2: Dance program content } \\
\hline Genre of dance & Focus on developing skills in a focused number of dance styles \\
\hline Enjoyment/group dynamics & $\begin{array}{l}\text { - } \quad \text { Establish a group dynamic early } \\
\text { - } \quad \text { Facilitate inclusion using games }\end{array}$ \\
\hline Relationship development and rapport & $\begin{array}{l}\text { - } \quad \text { Gather pupil input/evaluation } \\
\text { - } \quad \text { Use verbal encouragement \& feedback }\end{array}$ \\
\hline Creativity and ownership & $\begin{array}{l}\text { - } \quad \text { Progressively increase pupil input to foster confidence } \\
\text { - } \quad \text { Balance pupil input and ownership with structure and guidance }\end{array}$ \\
\hline Routine \& performance piece & $\begin{array}{l}\text { - } \quad \text { Work towards developing a performance piece } \\
\text { - } \quad \text { Encourage pupil decision making in what to perform and who to perform to }\end{array}$ \\
\hline
\end{tabular}

ers felt they lacked the knowledge, confidence and ability to teach dance.

"Yes I definitely think there would be a demand, [...] I do a little bit of dance, I teach half of Year 7, but I haven't got that much experience." (PE 4).

"It's just basically getting the pupils, or people, involved, and getting somebody actually to take the session... I'm not a dancer, or a dance specialist. I can't take the sessions." (PE 2).

School-based logistics. PE teachers highlighted challenges associated with running an extra-curricular program such as facilities and timetabling alongside existing activities.

"It would be space, where you would do it, and what other activities are going on outside because we have rounders and cricket and things going on, in different areas." (PE 4).

"Some schools have a stand-alone dance studio, but others might be competing with other activities and sports, and even subjects with the sports halls etc. So, it would have to be carefully planned and be integrated with the school's other extra-curricular activities." (PE 8).

Participant recruitment. Both PE teachers and dance specialists highlighted the intervention recruitment process as a key factor in a dance program. PE teachers suggested that a "dance taster session" which reflected the program and was delivered during a PE session to reach the entire year group, would maximise recruitment.

"That's always quite a good way of getting to, to the girls, definitely. Taster sessions.” (PE 1).

"Posters... or information giving, doesn't always lead to much uptake... a live link, is much better. Or an active link where there is some kind of personal interaction." (PE 8).

Cost of the program to pupils. Participants held mixed opinions of whether the dance program should be paid for by the pupils, or free of charge. Some PE teachers suggested that a fee may deter some pupils and their parents from signing up, resulting in a recruitment bias towards higher SES participants:

"I don't think you'd get, I don't think you'd get a representative sample." (PE 4).

"I think when money is involved, again, you get those kids who do everything anyway, ... and they have to pay for it, and they have to pay up front. And, so many parents said, can't afford it.” (PE 2).

However, some participants thought that a fee would increase perceived value and commitment to the program.

"I don't think there's anything wrong with kids paying to attend. If there is a charge, then it will help them to commit to it I think. On the other hand you don't want to price people out of the market. So it might be that a token charge might be made of say 50p a session.” (PE 8).

Behavior management and establishing expectations. PE teachers and dance teachers highlighted the importance of continuity between the behavior policies of the schools and those used by the external dance teachers. 
"Ground rules, because an external person going in, sometimes the school have behavior policies and things like that and the dance teacher needs to work alongside those policies to some degree, so that there are those kind of boundaries in place without being too strict with them. It's just aligning the dance teacher with a much broader knowledge of what's happening in school time and behavior policies." (Dance Teacher 7).

The dance teachers also stressed the importance of clarifying the expectations of both the teacher and pupils from the start of the dance intervention. However, they also highlighted the importance of achieving a balance of agreed rules and being too strict.

"You can draw up a contract between the student and the teacher and you say, this is what we expect of you, this is behavior, attendance, uniform and performance. What do you expect? As students on this project, what do you want from it?" (Dance Teacher 4).

"You have to have an approach that when it's out of school you need to be out of teacher mode, because out of school it's their choice to come. So you can't be too strict. But then it's laying those foundation and ground rules and boundaries still, so that it's not a free for all." (Dance Teacher, 7).

\subsection{Theme 2: Dance Program Content}

The dance teachers converged in their views of the key dance content that should guide the development of an extra-curricular school-based dance intervention. Factors included specifying a dance genre, structuring sessions to optimize ownership, enjoyment and teacher-pupil rapport and the inclusion of a performance element.

Genre of dance. The dance teachers suggested that participants should work towards learning one style of dance to facilitate the development and refinement of individual skills.

"I think it would be probably best either do one, or maybe at the most, two styles. Because that way you're going to get the most out of them and they're going to be able to learn more." (Dance Teacher 2).

Establishing enjoyment and group dynamics. The dance instructors noted the importance of activities which foster friendships and generate a group ethos:

"I would go ahead with name games, some ice breakers, particularly in the first couple of weeks. Because the key thing is, the group needs to get to know each other... and hopefully, they'll feel more included and want to come back because they are making new friends." (Dance Teacher 4).

"I would go in with a whole taster of games and activities, different styles, but very short, five, ten minute tasks, then move on to keep it really snappy." (Dance Teacher 7).
Relationship development and rapport. The dance teachers highlighted the importance of establishing a good relationship with the pupils. This was characterized by two-way communication, listening to pupil opinions and encouragement.

"You need to develop a good rapport where you are continually asking them for feedback as well and they won't come back if they didn't like it. So it's quite important that at the end of each session you say what have you enjoyed today, what has gone well, what shall we change for next time?” (Dance Teacher 10).

“...encouragement, constant feedback, letting them know how close they are to reaching their goal, or achievement, whether it's a show "it's looking really good for the show, can't wait to invite your parents" and especially if they've got their input then it would certainly start to be more fun and enjoyable." (Dance Teacher 1).

Creativity and ownership. All of the dance instructors noted the importance of student-directed time as a means of fostering ownership. The participants noted that the initial sessions should be mainly teacher-led with student-led time introduced and increased over the course of the intervention as the girls increase in confidence and competence.

"The first couple of sessions, it's mostly teacher-led because they might not have any dance vocabulary in their bodies. They might not be brave enough. So I would just give very simple choreographic task and games where they didn't even know where composing dances, they just felt like they were playing games to get them a bit more brave." (Dance Teacher 11).

It was suggested that student-led input would be enhance the development, confidence and creative thinking of the pupils whilst also giving them the opportunity of working with other pupils within the class.

"It encourages that ownership and attracts what you want to achieve and they certainly need a chance to put into action what they see, or they might have created their own little movements at home that they want to show off." (Dance Teacher 8).

The dance instructors highlighted a number of challenges that dance teachers might face with student-led time including keeping pupils engaged, dealing with pupils with varied abilities and providing sufficient structure to student-led tasks. They suggested a number of potential means of addressing these difficulties:

"I think keeping a really tight time frame, very clear structured tasks." "Right, I've taught you that sequence, I want you to put that together, three of you, all facing different directions, and add one more of your own." So it's very clear." (Dance Teacher 6).

"It is that role of just watch and see and step in if needed. Sometimes I'll go to a group and I'll just hover. 
And they're doing so well I'll just step back because they're doing all the right things, including everybody, not spending too much time chatting about other stuff." (Dance Teacher 9).

Routine and performance element. The PE teachers and dance teachers suggested that working towards a dance performance with the option of demonstrating what the pupils had learnt would positively influence their motivation, encourage engagement and create a sense of belonging amongst pupils.

"I would definitely build it up towards a performance. Absolutely, that's always got to be the aim." (Dance Teacher 11).

"The element of performance can take many different forms and I think that has to come from the young people to keep them engaged." (Dance teacher 7).

"We have an evening of gym and dance where they can show the work to their parents and those are always really powerful and really popular both in terms of reinforcing girls' attitudes and the likelihood they'll stay with dance and in a role modeling effect, inspiring others to want to take part." (PE 7).

\section{DISCUSSION}

The first aim of the present study was to engage PE teachers and dance teachers in the process of developing an extra-curricular dance program by identifying factors that might influence its design and delivery. PE teachers felt that there was a lack of dance provision in schools, and the majority lacked the knowledge, confidence and experience to teach dance. This is consistent with the findings of Youth Dance England [12] which highlights the lack of provision across schools in England and that many teachers who deliver dance within the national curriculum are general PE teachers with no dance qualifications. Youth Dance England have noted that priorities for dance in schools are: to improve the workforce of teachers delivering dance, to increase the accessibility of dance in the curriculum and during extra-curricular activities and to focus on the least engaged individuals. As such, one possible solution is to recruit specialist dance instructors to inspire and engage youth in dance as a form of PA.

In order to effectively recruit participants, an intervention must target all pupils within a school year group, be relevant, reflect current trends, be appropriate for and adaptable to the ability level of participants to be optimally challenging and encourage pupil input. Delivering a fun and exciting taster session may inspire and excite pupils about dance and encourage recruitment. These findings agree with the beliefs of adolescent girls identified in previous research which suggests that fun (of moving, having a sense of freedom, creativity, self-expression \& learning new skills), social interaction, teacher support and links to current trends are important in engaging adolescents in dance [19,20].

Logistical issues that were highlighted included aligning the program with current extra-curricular activities to avoid competition with other PA opportunities. Again this reflects previously identified perspectives of adolescent girls [19]. Such competition may influence recruitment and the composition of participant groups. It is therefore necessary to carefully target less active girls for whom attending an extra-curricular dance class would represent an addition to their weekly activities rather than a displacement of an alternative PA. Further, in line with previous work [21] both the PE teachers and dance teachers stressed the importance of establishing expectations for behavior and attendance. The findings suggest that aligning these with the school behavior policy is essential so that the intervention has clear and consistent guidelines which the participants are familiar with.

Findings were mixed with regards to whether the intervention should be free of charge or carry a fee. Some participants believed a fee would be a barrier to some pupils whereas others thought it would enhance the value pupils place on the program as it is common to incur a fee for extra-curricular activities. If a fee were charged, it would be important to balance cost with value for money and ensure that it does not prevent participation amongst low income groups. Further research using economic frameworks is required to explore adolescents' and parents' preferences with regards to financial charges for such programs.

Physical activity interventions should be grounded in theory to facilitate their development and to identify why and how they are effective or ineffective [22]. Accordingly, the second aim of this study was to use participants' perspectives to identify a theoretical framework with which to design a dance-based PA intervention. The opinions forwarded by dance teachers and PE teachers in the present study suggest that self-determination theory (SDT) [23] would provide an appropriate theoretical foundation. SDT is a theory of motivation which contends that motivation, well-being and behavioral engagement are optimized when individuals experience satisfaction of psychological needs of autonomy (i.e., being the origin of one's behavior), competence (i.e., feeling effective \& skilful in one's environment) and relatedness (i.e., feeling a sense of connectedness with others). In the present study, the participants' narratives referred to enhancing ownership, student-led learning, the progressive development of skills, building rapport and using small groups for learning which map on to the concepts of autonomy, competence and relatedness. SDT has previously been employed to understand cognitive and behavioral factors among dancers and need satisfaction in dance is associated with indicators of well-being 
[24].

In terms of dance program content, dance teachers' knowledge and experience can help to create a relevant, fun and enjoyable dance intervention whilst fostering a supportive relationship with and between the pupils. In line with the views of adolescent girls [19], dance teachers emphasized the development of participant ownership of the dance intervention. The social context such as the classroom climate created by teachers is an additional feature of SDT which emphasizes how teacher-created climates influence pupil motivation and psychological need satisfaction $[25,26]$. Dance teachers can enhance autonomous motivation and need satisfaction by 1 ) being autonomy-supportive (e.g., giving choice during dance sessions), 2) providing structure (e.g., clear expectations guidelines and rules) and 3) being interpersonally involved (e.g., showing interest and understanding pupils). These empowering strategies, many of which were articulated by the dance teachers and PE teachers in the present study and have previously been documented by adolescent dancers [20] and have positive effects on the motivation, need satisfaction and psychological wellbeing of dancers $[24,26]$.

\section{Limitations}

Although the sample size was small, we were able to triangulate the views of the PE and dance teachers and there was clear evidence of saturation where no new information was obtained within the later interviews. We are therefore confident that the data are an accurate representation of the views of dance teachers and PE teachers in the local area. A further limitation is that although participants offered their experiences of the teaching strategies that they have previously found to be successful, and there was consistency among participants in this regard, we are unable to identify the degree to which these were successful in engaging young people or whether their opinions reflected strategies that they believe would work rather than what is effective in practice.

\section{CONCLUSION}

The data presented have shown that an after school extra-curricular dance program would be welcomed in UK secondary schools. Developers of extra-curricular interventions need to respond to logistical challenges posed in school settings. A dance intervention can be grounded in behavioral theory and run by specialist dance teachers using a combination of teacher-led tasks and student- directed time with the aim of increasing PA. The intervention should focus on being fun, energetic and encouraging, work towards a dance performance element and developing pupils' skills and confidence to engage in dance and PA more broadly.

\section{ACKNOWLEDGEMENTS}

This work was supported by the National Prevention Research Initiative (http://npri.org.uk), consisting of the following funding partners: Alzheimer's research Trust; Alzheimer's Society; Biotechnology and Biological Sciences Research Council, British Heart Foundation; Cancer Research UK; Chief Scientist Office; Scottish Government Health Directorate; Department of Health; Diabetes UK; Economic and Social Research Council; Engineering and Physical Sciences Research Council; Health \& Social Care Research \& Development Office for Northern Ireland; Medical Research Council; The Stroke Association; Welsh Assembly Government and World Cancer Research Fund. This work was also supported by a Career Development Fellowship (to Dr. Jago) supported by the National Institute for Health Research. The views expressed in this publication are those of the authors and not necessarily those of the NHS, the National Institute for Health Research or the Department of Health.

\section{REFERENCES}

[1] Jago, R., Baranowski, T., Baranowski, J.C., Thompson, D. and Greaves, K.A. (2005) BMI from 3-6 y of age is predicted by TV viewing and physical activity, not diet. International Journal of Obesity, 29, 557-564. doi:10.1038/sj.ijo.0802969

[2] Jago, R., et al. (2008) Six-year change in youth physical activity and effect on fasting insulin and HOMA-IR. American Journal of Preventive Medicine, 35, 554-560. doi:10.1016/j.amepre.2008.07.007

[3] Schmalz, D.L., Deane, G.D., Birch, L.L. and Davison, K.K. (2007) A longitudinal assessment of the links between physical activity and self-esteem in early adolescent non-Hispanic females. Journal of Adolescent Health, 41, 559-65. doi:10.1016/j.jadohealth.2007.07.001

[4] Riddoch, C.J., et al. (2009) Prospective associations between objective measures of physical activity and fat mass in 12-14 year old children: The Avon Longitudinal Study of Parents and Children (ALSPAC). British Medical Journal, 339, Article ID: b4544. doi:10.1136/bmj.b4544

[5] Kimm, S.Y., et al. (2002) Decline in physical activity in black girls and white girls during adolescence. New England Journal of Medicine, 347, 709-715. doi:10.1056/NEJMoa003277

[6] Nader, P.R., Bradley, R.H., Houts, R.M., McRitchie, S.L. and O’Brien, M. (2008) Moderate-to-vigorous physical activity from ages 9 to 15 years. Journal of the American Medical Association, 300, 295-305. doi:10.1001/jama.300.3.295

[7] van Sluijs, E.M., McMinn, A.M. and Griffin, S.J. (2007) Effectiveness of interventions to promote physical activity in children and adolescents: Systematic review of controlled trials. British Medical Journal, 335, 703. doi:10.1136/bmj.39320.843947.BE

[8] Brown, T., Kelly, S. and Summerbell, C. (2007) Preven- 
tion of obesity: A review of interventions. Obesity Reviews, 8, 127-130.

doi:10.1111/j.1467-789X.2007.00331.X

[9] Chomitz, V.R., et al. (2009) Is there a relationship between physical fitness and academic achievement? Positive results from public school children in the Northeastern United States. Journal of School Health, 79, 30-37. doi:10.1111/j.1746-1561.2008.00371.x

[10] O’Donovan, T. and Kay, A. (2005) Focus on girls in sport. British Journal of Teaching Physical Education, 36, 2931.

[11] Beaulac, J., Olavarria, M. and Kristjansson, E. (2010) A community-based hip-hop dance program for youth in a disadvantaged community in Ottawa: Implementation findings. Health Promotion Practice, 11, 61S-69S. doi:10.1177/1524839909353738

[12] (2010) Young people's dance: A ten year vision 20102020 for the development of dance for children and young people in England. Australian WomenSport and Recreation Association, Panton Hill.

[13] O’Neill, J.R., Pate, R.R. and Hooker, S.P. (2011) The contribution of dance to daily physical activity among adolescent girls. International Journal of Behavioral $\mathrm{Nu}$ trition and Physical Activity, 8, 87. doi:10.1186/1479-5868-8-87

[14] (2008) Youth sports trust, audit of dance provision in English schools 2006/2007.

[15] Pate, R.R. and O’Neill, J.R. (2009) After-school interventions to increase physical activity among youth. British Journal of Sports Medicine, 43, 14-18. doi:10.1136/bjsm.2008.055517

[16] Jago, R. and Sebire, S.J. (2012) Publishing pilot and feasibility evaluations of behavioural interventions: Implications for Preventive Medicine. Preventive Medicine, 55, 548-549. doi:10.1016/j.ypmed.2012.07.005

[17] Michie, S. and Prestwich, A. (2010) Are interventions theory-based? Development of a theory coding scheme. Health Psychology, 29, 1-8. doi:10.1037/a0016939
[18] Braun, V. and Clarke, V. (2006) Using thematic analysis in psychology. Qualitative Research in Psychology, 3, 77 101. doi:10.1191/1478088706qp063oa

[19] Jago, R., et al. (2011) Adolescent girls' and parents' views on recruiting and retaining girls into an after-school dance intervention: Implications for extra-curricular physical activity provision. International Journal of Behavioral Nutrition and Physical Activity, 8, 91. doi:10.1186/1479-5868-8-91

[20] Stinson, S.W. (1997) A question of fun: Adolescent engagement in dance education. Dance Research Journal, 29, 49-69. doi:10.2307/1478734

[21] Simonsen, B., Fairbanks, S., Briesch, A. and Myers, D. (2008) Evidence-based practices in classroom management: Considerations for research to practice. Education and Treatment of Children, 31, 351-380. doi:10.1353/etc.0.0007

[22] Brug, J., Oenema, A., and Ferreira, I. (2005) Theory, evidence and intervention mapping to improve behavior nutrition and physical activity interventions. International Journal of Behavioral Nutrition \& Physical Activity, 2, 2. doi:10.1186/1479-5868-2-2

[23] Deci, E.L. and Ryan, R.M. (2000) The "what" and "why" of goal pursuits: Human needs and the self-determination of behavior. Psychological Inquiry, 11, 227-268. doi:10.1207/S15327965PLI1104 01

[24] Quested, E. and Duda, J.L. (2010) Exploring the social-environmental determinants of well- and ill-being in dancers: A test of basic needs theory. Journal of Sport \& Exercise Psychology, 32, 39-60.

[25] Reeve, J. (2002) Self-determination theory applied to educational settings: In: Deci, E.L. and Ryan, R.M., Eds., Handbook of Self-Determination Theory Research, The University of Rochester Press, New York, 183-204.

[26] Quested, E. and Duda, J.L. (2011) Perceived autonomy support, motivation regulation and the self-evaluative tendencies of student dancers. Journal of Dance Medicine \& Science, 15, 3-14. 